Supporting Information 


\section{General Preparation of Three-dimensional Porous Metal Oxide Foams Coated with Nitrogen-doped Carbon for Enhanced Lithium Storage}

$\mathrm{Ke} \mathrm{Lu}^{1}$, Jiantie $\mathrm{Xu}^{2}$, Jintao Zhang ${ }^{1, *}$, Bin Song ${ }^{3}$, and Houyi $\mathrm{Ma}^{1, *}$

${ }^{1}$ Key Laboratory for Colloid and Interface Chemistry of State Education Ministry, School of Chemistry and Chemical Engineering, Shandong University, Jinan 250100, China.

${ }^{2}$ Department of Macromolecular Science and Engineering, School of Engineering, Case Western Reserve University, Cleveland, Ohio 44106, USA.

${ }^{3}$ Jiangsu Key Laboratory for Carbon-Based Functional Materials and Devices, Institute of Functional Nano and Soft Materials (FUNSOM), Soochow University, Suzhou 215123, China.

*To whom correspondence should be addressed

E-mail: jtzhang@sdu.edu.cn; hyma@sdu.edu.cn.

KEYWORDS. Porous structure $\cdot$ metal oxide foam $\cdot$ nitrogen-doped carbon $\cdot$ lithium storage $\cdot$ surfactant 

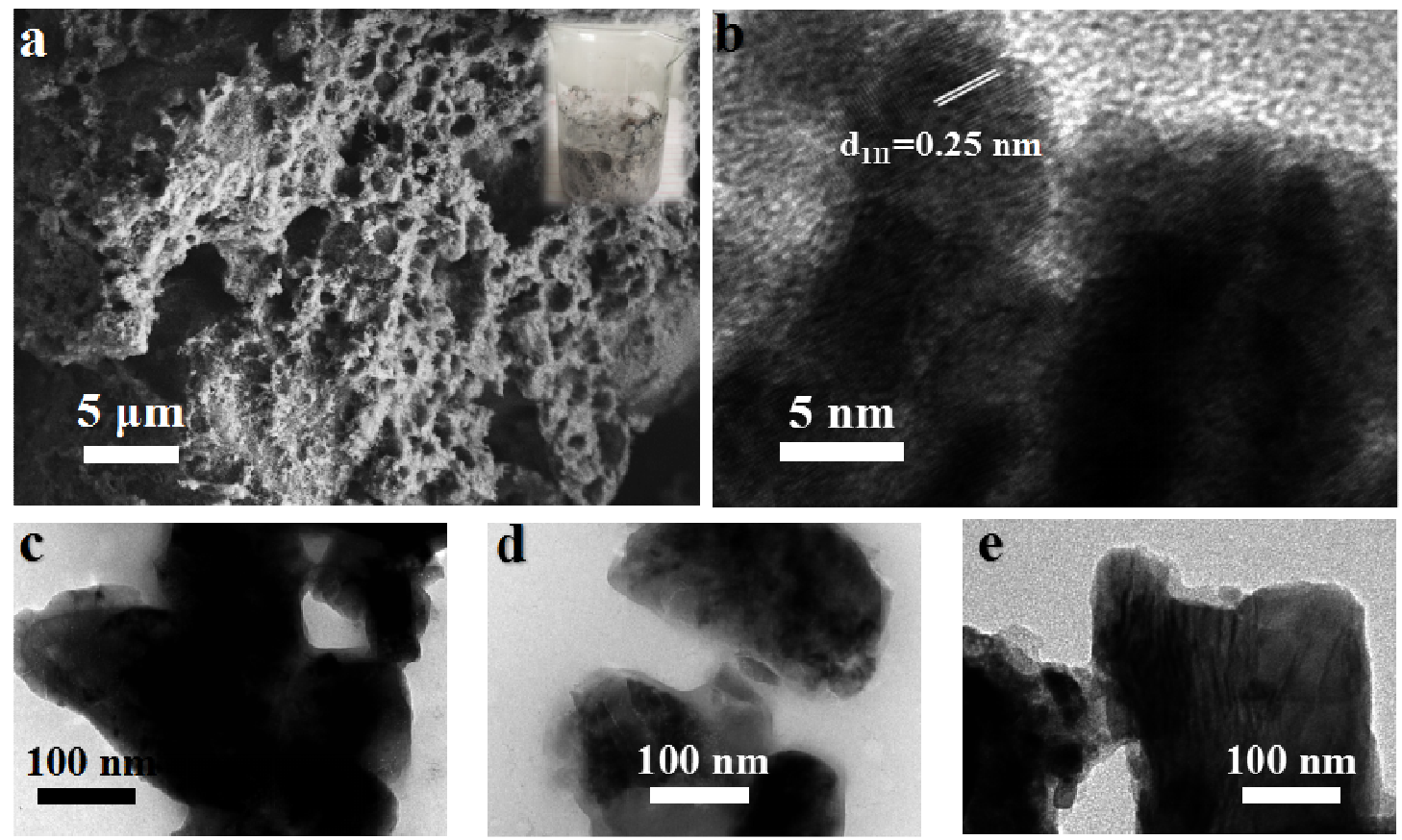

Figure S1. SEM images (a) and HRTEM images (b) of the MnO@N-C foam. Inset is the digital photo image of $\mathrm{MnO}_{2}$ foam. The exposed lattice fringes (b) exhibit a spacing of $0.25 \mathrm{~nm}$, corresponding to the (111) plane of $\mathrm{MnO}$. TEM images of $\mathrm{MoO}_{2} @ \mathrm{~N}-\mathrm{C}$ (c), $\mathrm{VO}_{2} @ \mathrm{~N}-\mathrm{C}(\mathrm{d})$, and $\mathrm{MnO} @ \mathrm{~N}-\mathrm{C}(\mathrm{e})$. 

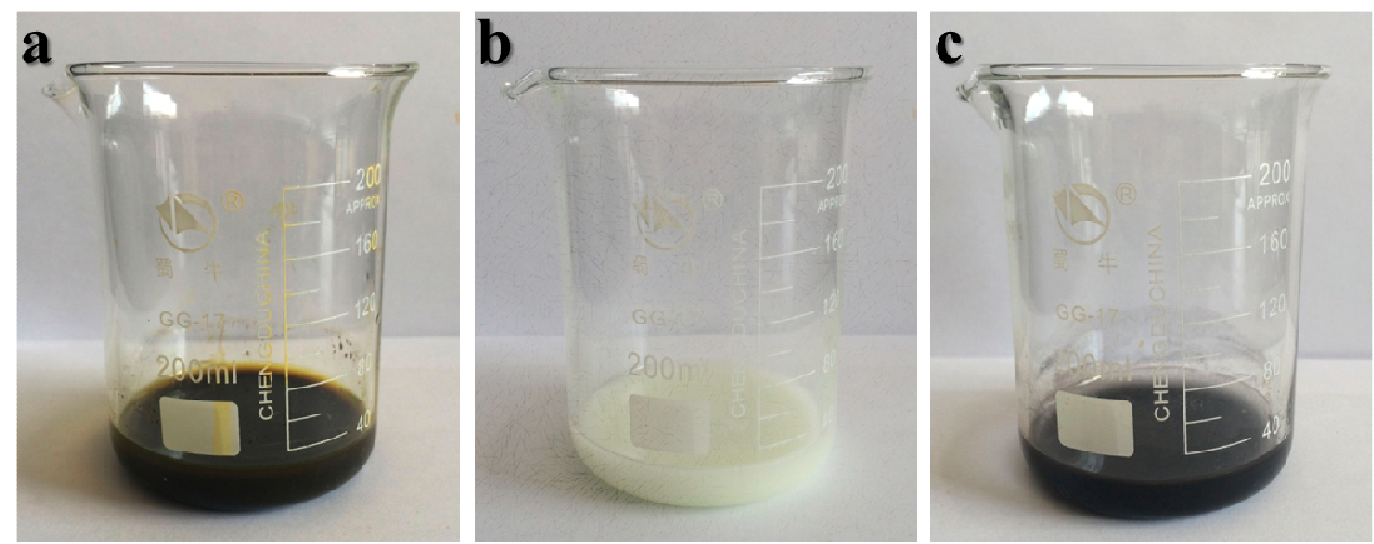

Figure S2. Digital photo images of (a) $\mathrm{V}_{2} \mathrm{O}_{5}$, (b) $\mathrm{MoO}_{3}$, and (c) $\mathrm{MnO}_{2}$ synthesized without the addition of HDA. It can be seen that metal oxide foams cannot be formed in the absence of surfactant. 


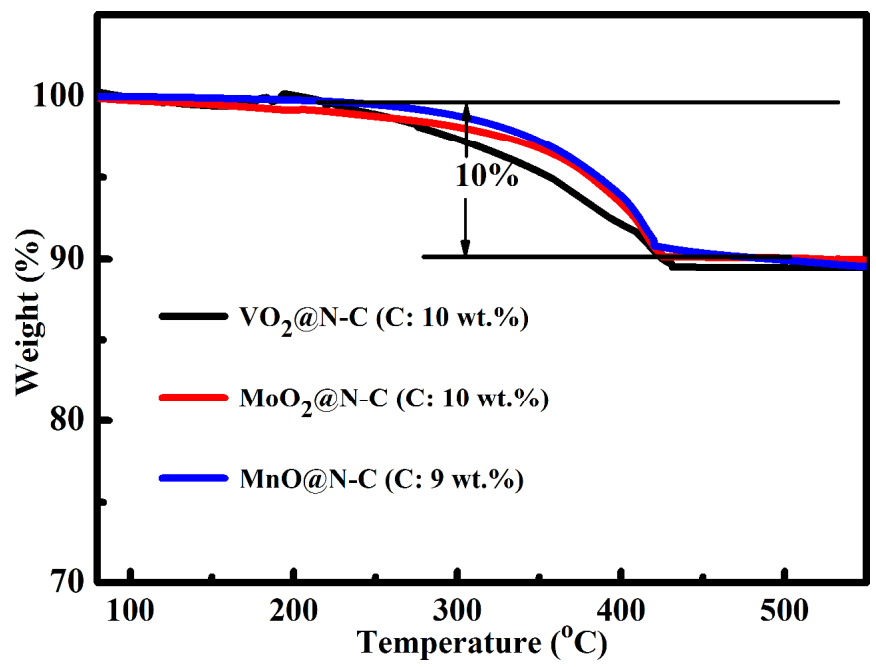

Figure S3. Thermal gravimetric analysis for $\mathrm{VO}_{2} @ \mathrm{~N}-\mathrm{C}, \mathrm{MoO}_{2} @ \mathrm{~N}-\mathrm{C}$ and $\mathrm{MnO} @ \mathrm{~N}-\mathrm{C}$. 

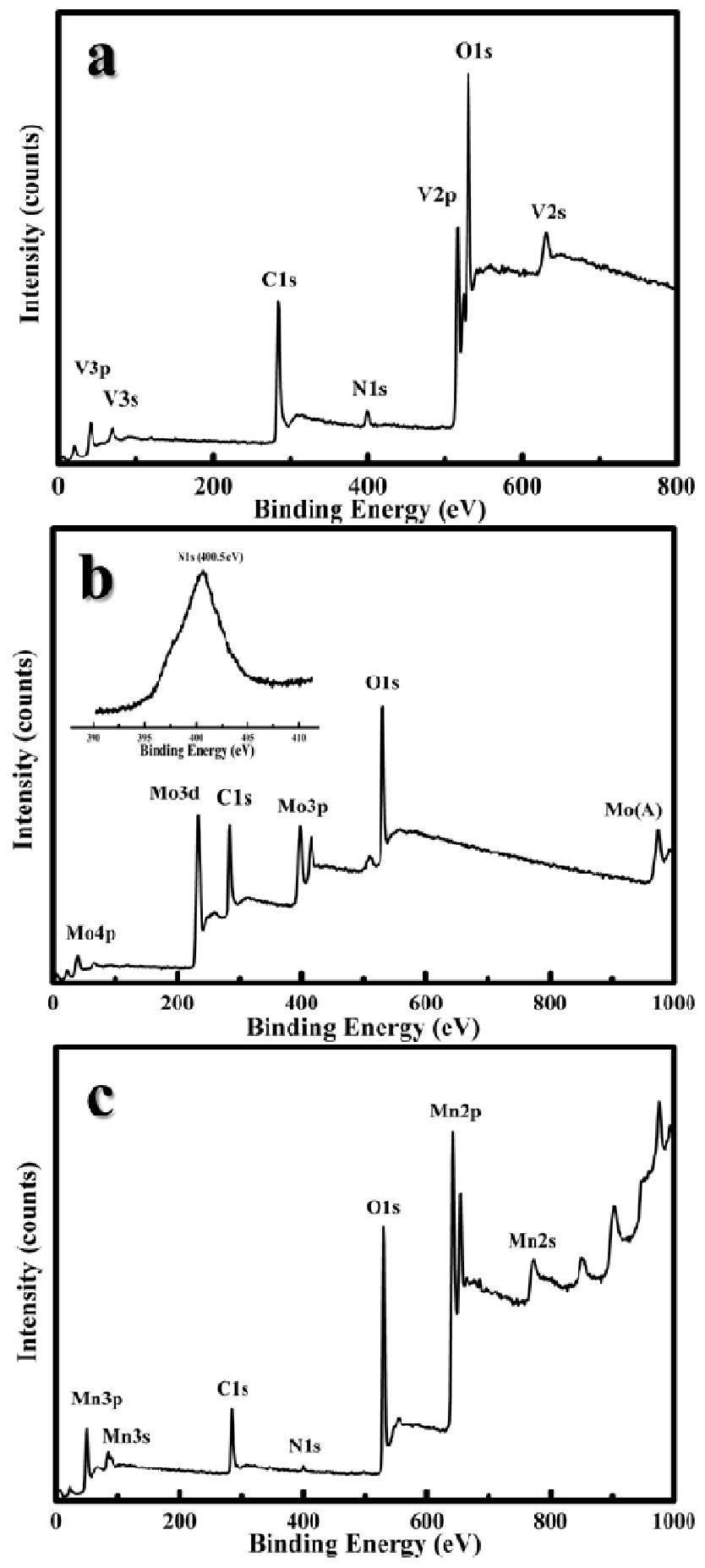

Figure S4. XPS survey spectra of $\mathrm{VO}_{2} @ \mathrm{~N}-\mathrm{C}(\mathrm{a}), \mathrm{MoO}_{2} @ \mathrm{~N}-\mathrm{C}$ (b) and $\mathrm{MnO} @ \mathrm{~N}-\mathrm{C}$ (c). 


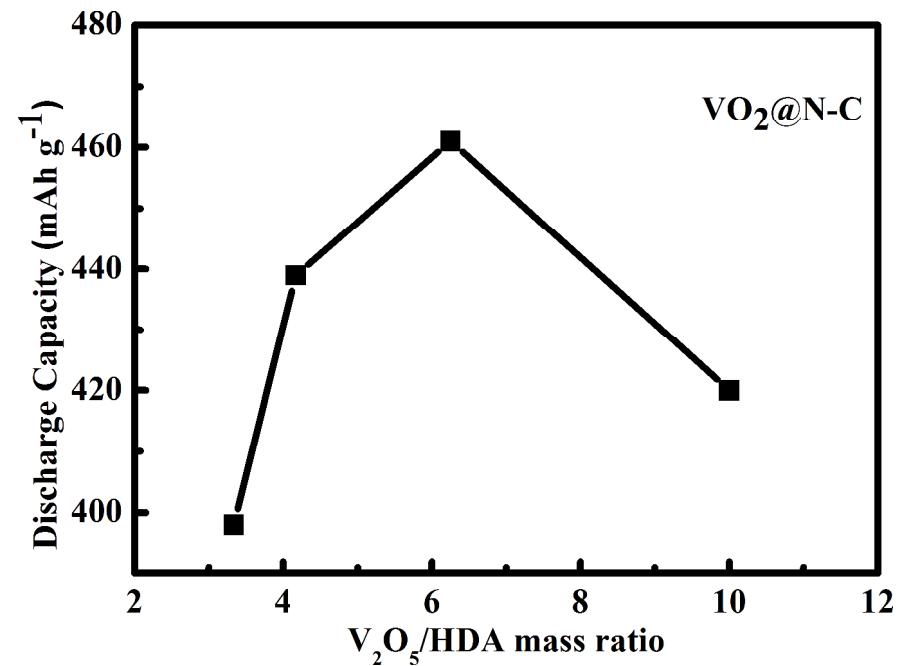

Figure S5. Capacities calculated from the discharge curves as a function of $\mathrm{V}_{2} \mathrm{O}_{5} / \mathrm{HDA}$ mass ratio at $30 \mathrm{~mA} \mathrm{~g}^{-1}$.

To optimize the capacity performance, the $\mathrm{VO}_{2} @ \mathrm{~N}-\mathrm{C}$ samples were prepared by changing the mass ratio of vanadium oxide to HDA. It can be seen that the maximal capacity is achieved at the ratio of 6.25 . 

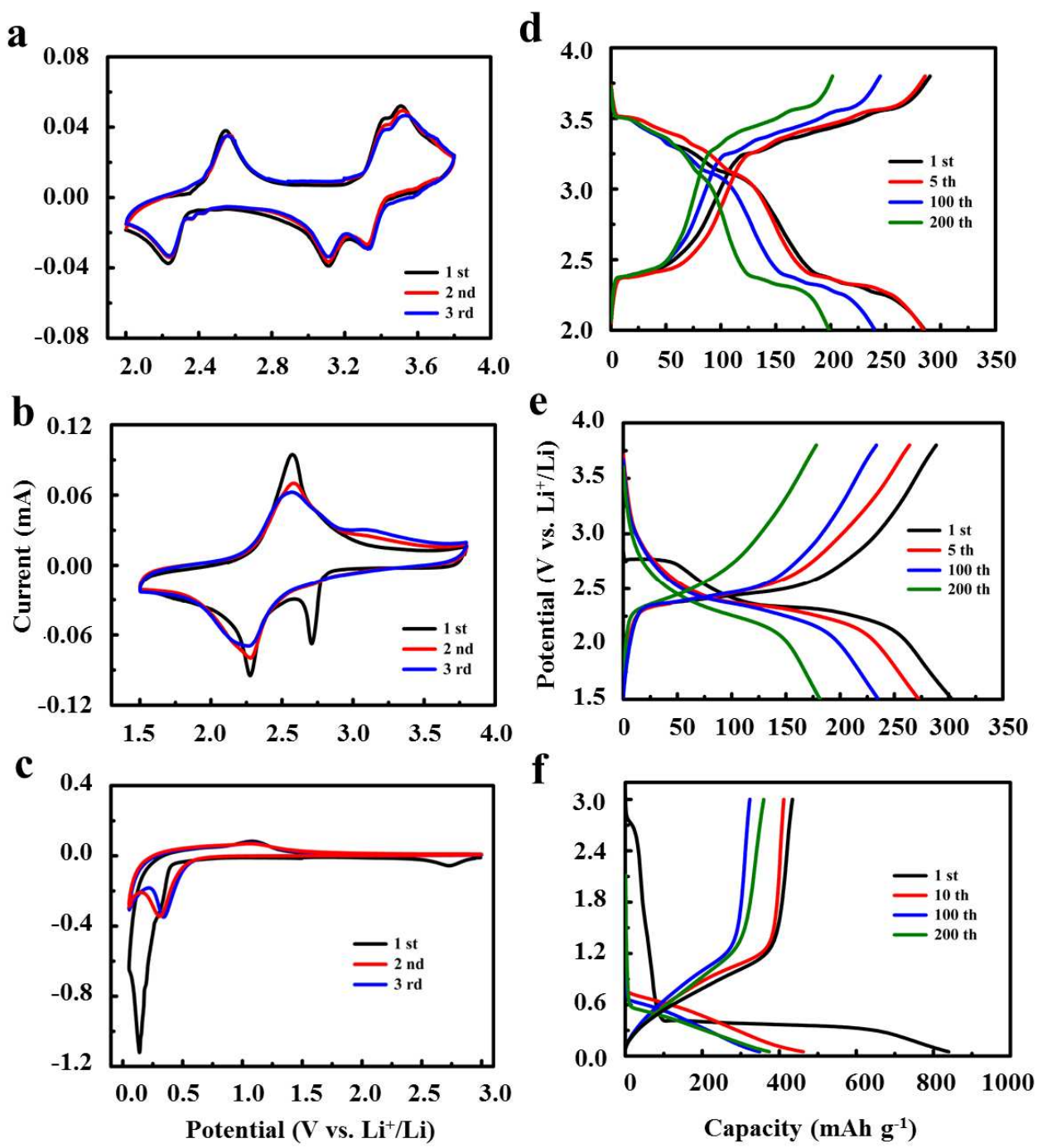

Figure S6. Cyclic voltammogram curves of (a) $\mathrm{V}_{2} \mathrm{O}_{5}$, (b) $\mathrm{MoO}_{3}$, and (c) $\mathrm{MnO}_{2}$ at a scan rate of $0.1 \mathrm{mV} \mathrm{s}^{-1}$. Galvanostatic charge/discharge curves (d) $\mathrm{V}_{2} \mathrm{O}_{5}$, (e) $\mathrm{MoO}_{3}$, and (f) $\mathrm{MnO}_{2}$ foam materials (for $\mathrm{V}_{2} \mathrm{O}_{5}$ and $\mathrm{MoO}_{3}$, the current density: $30 \mathrm{~mA} \mathrm{~g}^{-1}$, for $\mathrm{MnO}_{2}$ current density: $100 \mathrm{~mA} \mathrm{~g}^{-1}$ ).

The $\mathrm{CV}$ curves of the as-prepared $\mathrm{MoO}_{3}$ foam show the substantial variation of redox peaks in comparison with the initial cycle. Typically, the absence of the peak at around $2.75 \mathrm{~V}$ due to the irreversible lithium insertion suggests the phase transformation to a favorable one with the highly reversible redox peaks at $2.26 / 2.57$ $\mathrm{V}$ in the subsequent cycles. In good agreement with the CV curves, the initial discharge curve with two plateau regions gives a capacity of as high as $302 \mathrm{~mA} \mathrm{~h} \mathrm{~g}^{-1}$. 
It can be seen that the discharge and charge plateaus generally remain stable over the repeated cycles, indicating the good structural reversibility. 

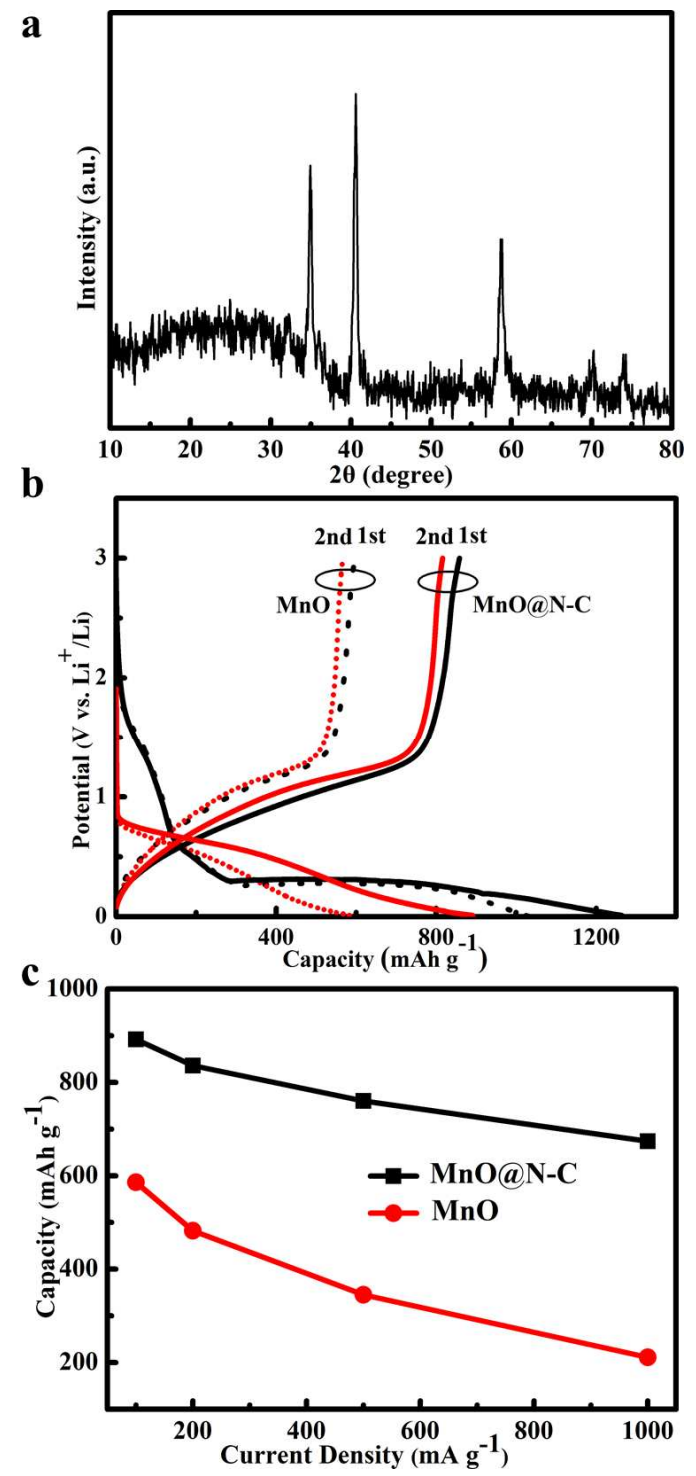

Figure S7. XRD pattern of $\mathrm{MnO}$ (a). Galvanostatic discharge/charge curves of $\mathrm{MnO} @ \mathrm{~N}-\mathrm{C}$ and $\mathrm{MnO}$ (b). Capacity calculated from the charge/discharge curves at various current densities (c).

To demonstrate of the crucial role of carbon networks for Li storage, pure $\mathrm{MnO}$ foam was prepared by reduction of $\mathrm{MnO}_{2}$ foam in the presence of hydrogen ( $7 \mathrm{vol} \%$ ). The XRD pattern (Figure S7a) can be indexed to the face-centered cubic $\mathrm{MnO}$ (JCPDS no. 07-0230). It can be seen that the performance of $\mathrm{MnO}$ can be enhanced in the presence of carbon coating. 

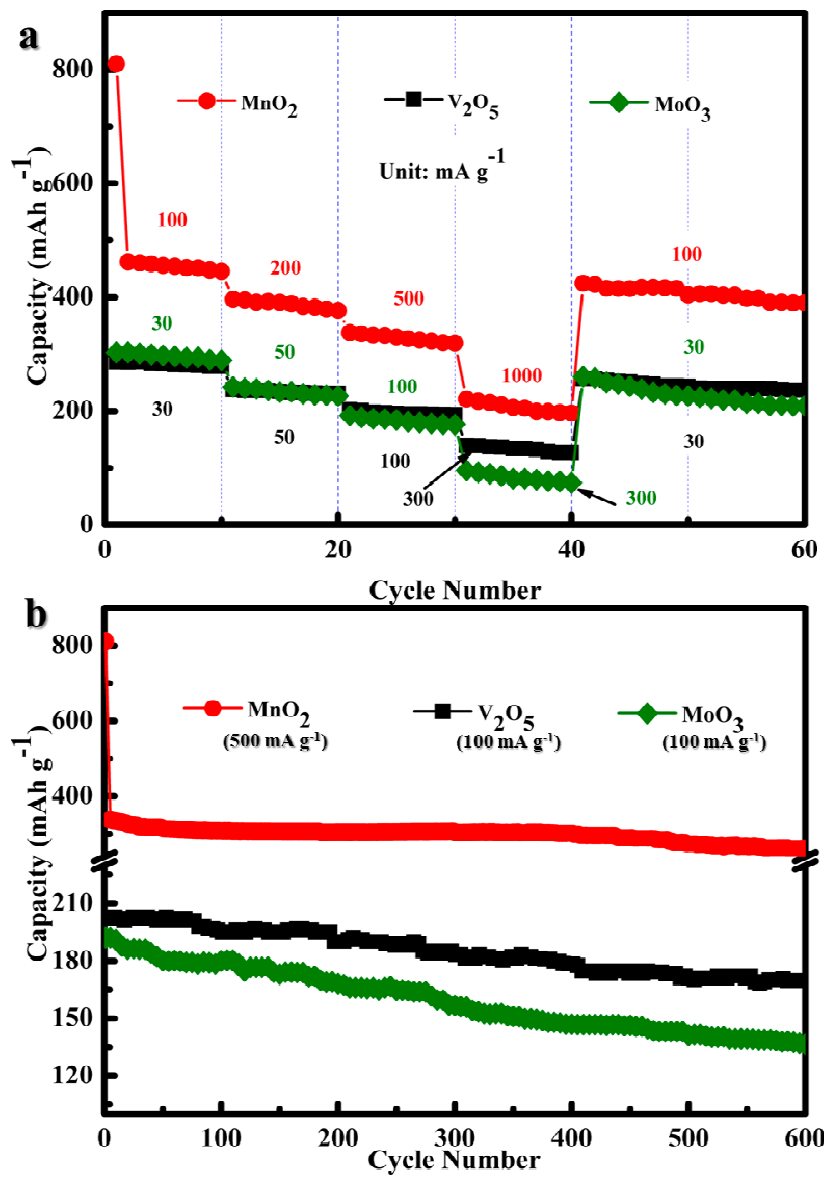

Figure S8. Rate (a) and cycling performances (b) of different materials.

The rate performance of the electrode materials was tested by varying the current density. When the current was restored to the initial current density after 40 cycles, around 89,86 , and $91 \%$ of the initial specific capacity for $\mathrm{V}_{2} \mathrm{O}_{5}, \mathrm{MoO}_{3}$, and $\mathrm{MnO}_{2}$ can be recovered. When the current density was increased by 10 times (30 to $300 \mathrm{~mA}$ $\mathrm{g}^{-1}$ or 100 to $1000 \mathrm{~mA} \mathrm{~g}^{-1}$ ), the capacity retention of $\mathrm{V}_{2} \mathrm{O}_{5}, \mathrm{MoO}_{3}$, and $\mathrm{MnO}_{2}$ were about 71,63 , and 72\%, exhibiting a good high-rate performance. The reversible capacity of $\mathrm{V}_{2} \mathrm{O}_{5}, \mathrm{MoO}_{3}$, and $\mathrm{MnO}_{2}$ foams are 166.6, 135.9, and $257.5 \mathrm{mAh} \mathrm{g}^{-1}$ after 600 cycles, with the capacity retention of around 82.5, 70.8, and $76.1 \%$ (for the second cycle), respectively. 

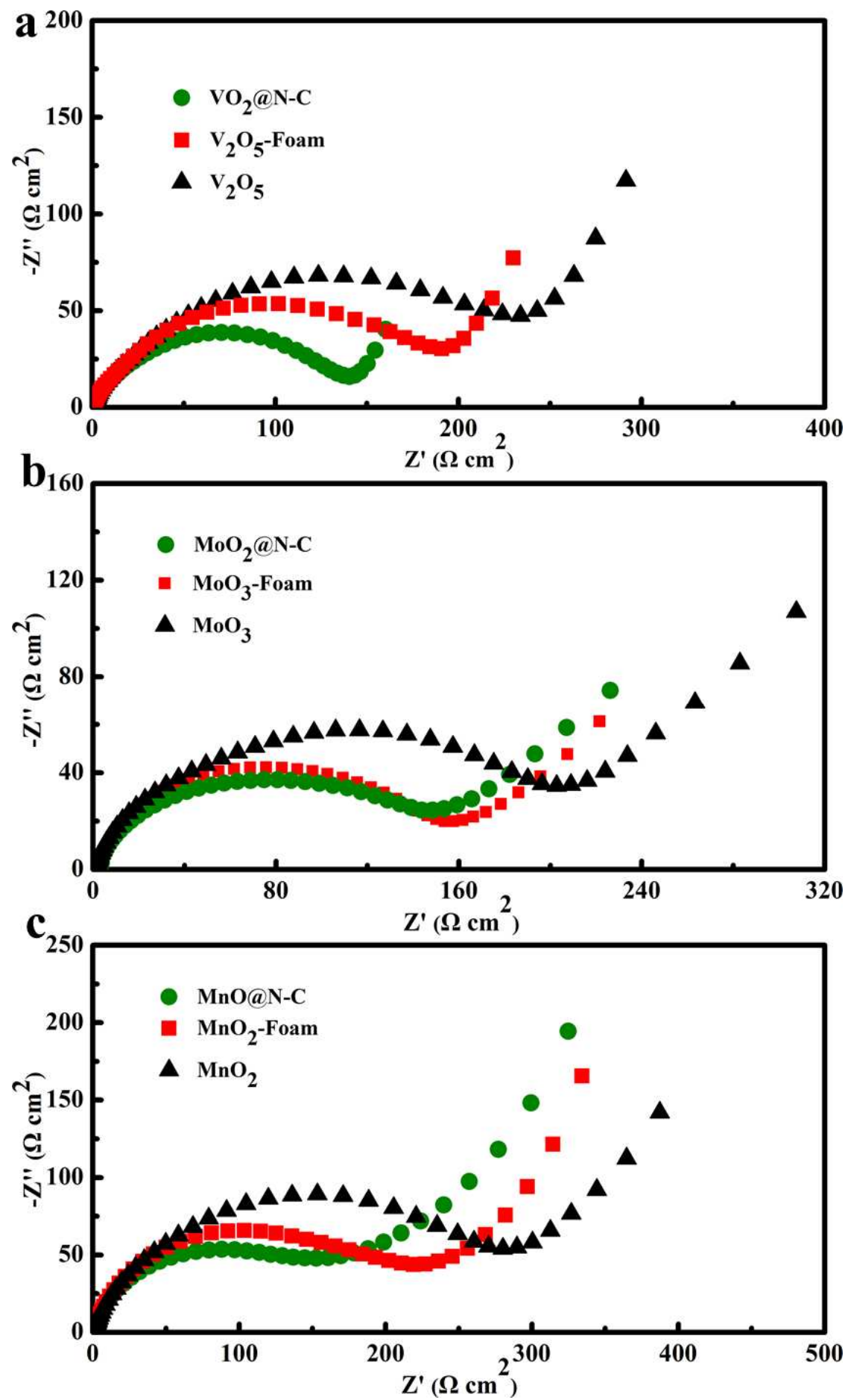

Figure S9. Nyquist plots of different electrode materials. (a) V-based metal oxide, (b) Mo-based metal oxide, and (c) Mn-based metal oxide materials. 
Table S1. The capacities of metal oxides@N-C at various current densities.

\begin{tabular}{ccc}
\hline Sample & Current density $\left(\mathbf{m A ~}^{\mathbf{- 1}}\right)$ & Capacity $\left(\mathbf{m A h ~}^{\mathbf{- 1}}\right)$ \\
\hline $\mathrm{VO}_{2} @ \mathrm{~N}-\mathrm{C}$ & 30 & 461 \\
& 50 & 437 \\
& 100 & 402 \\
& 200 & 369 \\
& 500 & 332.8 \\
& 1000 & 269 \\
\hline $\mathrm{MoO}_{2} @ \mathrm{~N}-\mathrm{C}$ & 100 & $856^{1 \mathrm{st}} / 613^{2 \mathrm{nd}}$ \\
& 200 & 565 \\
& 500 & 520.5 \\
& 1000 & 465 \\
\hline $\mathrm{MnO} @ \mathrm{~N}-\mathrm{C}$ & 100 & $1265^{1 \mathrm{st}} / 892^{2 \mathrm{nd}}$ \\
& 200 & 836 \\
& 500 & 760 \\
& 1000 & 674 \\
\hline
\end{tabular}


Table S2. The comparison of vanadium oxides as active materials for Li storage.

\begin{tabular}{|c|c|c|c|c|}
\hline Materials & $\begin{array}{c}\text { Potential } \\
\text { range } \\
\left.\text { (V vs. } \mathrm{Li}^{+} / \mathbf{L i}\right)\end{array}$ & 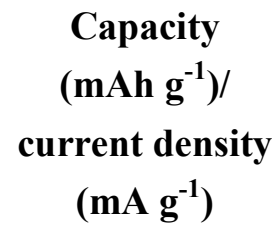 & Cycling stability/cycles & Citation \\
\hline $\mathrm{VO}_{2} / \mathrm{C}$ & $2-3$ & $219 / 50$ & $85 \% / 100\left(100 \mathrm{~mA} \mathrm{~g}^{-1}\right)$ & $\mathrm{S} 1$ \\
\hline $\mathrm{V}_{2} \mathrm{O}_{5}$ & $2-4$ & $275 / 294$ & $88.4 \% / 200\left(294 \mathrm{~mA} \mathrm{~g}^{-1}\right)$ & $\mathrm{S} 2$ \\
\hline \multicolumn{5}{|l|}{ Microspheres } \\
\hline $\mathrm{N}-\mathrm{G}-\mathrm{VO}_{2}$ & $1.5-4$ & $418 / 50$ & $60 \% / 50\left(50 \mathrm{~mA} \mathrm{~g}^{-1}\right)$ & $\mathrm{S} 3$ \\
\hline $\mathrm{V}_{2} \mathrm{O}_{5}$ & $2-4$ & $256 / 100$ & $89 \% / 50\left(100 \mathrm{~mA} \mathrm{~g}^{-1}\right)$ & S4 \\
\hline $\mathrm{V}_{2} \mathrm{O}_{5} / \mathrm{C}$ & $2-4$ & $297 / 1000$ & $97.3 \% / 50\left(1 \mathrm{~A} \mathrm{~g}^{-1}\right)$ & S5 \\
\hline $\mathrm{V}_{2} \mathrm{O}_{5}$ & $2.75-4$ & $427 / 7.5$ & $30 \% / 20\left(7.5 \mathrm{~mA} \mathrm{~g}^{-1}\right)$ & S6 \\
\hline $\mathrm{VO}_{2}$-Graphene & $1.5-3.5$ & $415 / 196$ & $93 \% / 1000\left(37.2 \mathrm{~A} \mathrm{~g}^{-1}\right)$ & S7 \\
\hline $\mathrm{VO}_{2}$ Hollow & $2-3$ & $203 / 100$ & $90 \% / 100\left(100 \mathrm{~mA} \mathrm{~g}^{-1}\right)$ & $\mathrm{S} 8$ \\
\hline \multicolumn{5}{|l|}{ Microspheres } \\
\hline $\mathrm{V}_{2} \mathrm{O}_{5}$ Foam & & $237 / 50$ & $82.5 \% / 600\left(100 \mathrm{~mA} \mathrm{~g}^{-1}\right)$ & This \\
\hline VO & $2-3.8$ & $438 / 50$ & $87.5 \% / 600\left(100 \mathrm{~mA} \mathrm{~g}^{-1}\right)$ & work \\
\hline
\end{tabular}




\section{REFERENCES}

S1 Mai, L. Q.; Wei, Q. L.; An, Q. Y.; Tian, X. C.; Zhao, Y. L.; Xu, X.; Xu, L.; Chang, L.; Zhang, Q. J. Noscroll Buffered Hybrid Nanostructural $\mathrm{VO}_{2}(\mathrm{~B})$ Cathodes for High-Rate and Long-Life Lithium Storage. Adv. Mater. 2013, 25, 2969-2973.

S2 Dong, Y.; Wei, H.; Liu, W.; Liu, Q.; Zhang, W.; Yang, Y. Template-Free Synthesis of $\mathrm{V}_{2} \mathrm{O}_{5}$ Hierarchical Nanosheet-Assembled Microspheres with Excellent Cycling Stability. J. Power Sources 2015, 285, 538-542.

S3 Nethravathi, C.; Rajamathi, C. R.; Rajamathi, M.; Gautam, U. K.; Wang, X.; Golberg, D.; Bando, Y. N-Doped Graphene- $\mathrm{VO}_{2}(\mathrm{~B})$ Nanosheet-Built 3D Flower Hybrid for Lithium Ion Battery. ACS Appl. Mater. Interfaces 2013, 5, 2708-2714.

S4 Pan, A. Q.; Wu, H. B.; Yu, L.; Lou, X. W. Template-Free Synthesis of $\mathrm{VO}_{2}$

Hollow Microspheres with Various Interiors and Their Conversion into $\mathrm{V}_{2} \mathrm{O}_{5}$ for Lithium-Ion Batteries. Angew. Chem., Int. Ed. 2013, 125, 2282-2230.

S5 Zhang, X. F.; Wang, K. X.; Wei, X.; Chen, J. S. Carbon-Coated $\mathrm{V}_{2} \mathrm{O}_{5}$ Nanocrystals as High Performance Cathode Material for Lithium Ion Batteries. Chem. Mater. 2011, 23, 5290-5292.

S6 Ragupathy, P.; Shivakumara, S.; Vasan, H. N.; Munichandraiah, N. Preparation of Nanostrip $\mathrm{V}_{2} \mathrm{O}_{5}$ by the Polyol Method and Its Electrochemical Characterization as Cathode Material for Rechargeable Lithium Batteries. J. Phys. Chem. C 2008, 112, 16700-16707.

S7 Yang, S.; Gong, Y.; Liu, Z.; Zhan, L.; Hashim, D. P.;Ma, L.; Vajtai, R.; Ajayan, P. M. Bottom-up Approach toward Single-Crystalline $\mathrm{VO}_{2}$-Graphene Ribbons as Cathodes for Ultrafast Lithium Storage. Nano Lett. 2013, 13, 1596-1601.

S8 Niu, C. J.; Meng, J. S.; Han, C. H.; Zhao, K. N.; Yan, M. Y.; Mai, L. Q. VO Nanowires Assembled into Hollow Microspheres for High-Rate and Long-Life Lithium Batteries. Nano Lett. 2014, 14, 2873-2878. 